\title{
On the structural peculiarities of self-reinforced composite materials based on UHMWPE fibers
}

\author{
Dmitry Zherebtsov ${ }^{1, *}$, Dilyus Chukov ${ }^{1}$, Isabelle Royaud ${ }^{2}$, Marc Ponçot ${ }^{2,3}$, Ilya Larin ${ }^{1}$, Eugene S. Statnik ${ }^{4}$, Taisia \\ Drozdova 5, Alexey Kirichenko ${ }^{6}$, Alexey Salimon ${ }^{4,1}$, Galal Sherif 1,7, Cyril Besnard ${ }^{8}$, and Alexander M. Korsunsky ${ }^{8,4}$
}

1 Center for Composite Materials, National University of Science and Technology "MISiS", Moscow 119049, Russia; Dil_Chukov@mail.ru (D.I.); elijah-larin@yandex.ru (I.I.)

2 Université de Lorraine, CNRS, IJL, F-54000 Nancy, France; Isabelle.Royaud@univ-lorraine.fr

3 Université de Lorraine, CNRS, LabEX “DAMAS”, F-57000 Metz, France; Marc.Poncot@univ-lorraine.fr

4 HSM lab, Center for Energy Science and Technologies, Skolkovo Institute of Science and Technology, Moscow 121205, Russia; eugene.statnik@skoltech.ru (E.S.); a.salimon@skoltech.ru (A.I.)

5 Technological Institute for Superhard and Novel Carbon Materials, Troitsk 108840, Russia; T.Shpitontseva@mail.ru

6 State Research Center of Russian Federation, Troitsk Institute for Innovation and Fusion Research, Troitsk 108840, Russia; akir73@mail.ru

7 Production and Design Dept., Faculty of Engineering, Minia University, Minia 61111, Egypt; eng_galal_emad@mu.edu.eg (G.S.)

8 MBLEM, Department of Engineering Science, University of Oxford, Oxford OX1 3PJ, UK; cyril.besnard@eng.ox.ac.uk (C.B.); alexander.korsunsky@eng.ox.ac.uk (AMK)

* $\quad$ Correspondence: Dmitry Zherebtsov@bk.ru (D.D.)

\begin{abstract}
The structure of self-reinforced composites (SRCs) based on ultra-high molecular weight polyethylene (UHMWPE) was studied by means of Wide-Angle X-Ray Scattering (WAXS), X-Ray tomography, Raman spectroscopy, Scanning Electron Microscopy (SEM) and in situ tensile testing in combination with advanced processing tools like Avizo, ImageJ, and Ncorr to determine the correlation between the processing conditions, on the one hand, and the molecular structure and mechanical properties, on the other. SRCs were fabricated by hot compaction of UHMWPE fibers at different pressure and temperature combinations without addition of polymer matrix or softener. It was found by WAXS that higher compaction temperatures led to more extensive melting of fibers with the corresponding reduction of the Herman's factor reflecting the degree of molecular orientation, while the increase of hot compaction pressure suppressed the melting of fibers within SRCs at a given temperature. X-Ray tomography proved the absence of porosity while polarized light Raman spectroscopy measurements for both longitudinal and perpendicular fiber orientations showed qualitatively the anisotropy of SRC samples. SEM revealed that the matrix was formed by interlayers of molten polymer entrapped between fibers in SRCs. Moreover, in situ tensile tests demonstrated the increase of Young's modulus and tensile strength with increasing temperature.
\end{abstract}

Keywords: Self-reinforced composites (SRCs); UHMWPE fibers; hot compaction; Avizo; Herman's factor; Digital Image Correlation (DIC); ImageJ.

\section{Introduction}

Capiati and Porter were the first to put forward the concept of self-reinforcement for composite materials in 1975 [1]. Self-reinforced composite (SRC) materials based on polyolefins are well studied and reported in a range of numerous reviews and books [2-4]. Nowadays, SRC materials based on polypropylene (PP) are commercially available, e.g. Curv ${ }^{\circledR}[5]$, Armordone [6], PURE [7], etc. However, there are no commercially affordable SRC materials based on ultra-high molecular weight polyethylene (UHMWPE).

Polyethylene (PE) is considered to be more attractive for mechanical applications in most early studies since the theoretical elastic modulus of the linear PE molecule ( 250 
GPa) is much higher than the modulus of the helical PP molecule ( $43 \mathrm{GPa}$ ) [4]. For this reason, it has been argued that the highest achievable modulus of the final structure is likely to depend on the characteristic properties of individual fibers, so that higher stiffness should be possible with PE fibers. The highest tensile strength and modulus of PE-based SRC were reported to be equal to 1.3 GPa and 73.9 GPa respectively [8], while the same parameters for PP-based SRCs reached 0.17 GPa and 3.13 GPa respectively [9]. Similar observations were made regarding the comparison of SRCs in terms of flexural properties $[8,10]$.

The main widely expected advantage of SRCs is the guaranteed strong bonding between matrix and reinforcement components in this type of composite material that ensures good mechanical strength. The system can also be especially attractive for applications requiring chemical inertness. Also, UHMWPE SRCs have lower density than traditional composites due to the lower density of polymeric reinforcing fibers compared to analogues such as carbon or glass fibers (approximately $1.0 \mathrm{~g} / \mathrm{cm}^{3}$ versus $1.8-2.5$ $\mathrm{g} / \mathrm{cm}^{3}$ ). Moreover, SRCs should possess excellent recyclability due to their thermoplastic nature and the absence of the separation stage required to recycle traditional composites, although their recyclability has not been extensively studied previously.

Broadly speaking, the fabrication route of SRCs can be represented by two main concepts: a) SRCs are manufactured from single starting polymer stock; and b) SRCs are produced using distinct components of the same polymer type. The second concept allows achieving a wide temperature window that is important for stable properties of SRC's end-product [11]. For this reason, there are numerous studies of SRCs based on the following composition: high density PE(HDPE)/low density PE (LDPE) [12], UHMWPE/HDPE [13], ultra-high-modulus PE/LDPE [14], etc. However, the difference in the polymer type can have negative effect on recyclability in further valuable applications. Besides, UHMWPE has the highest mechanical and tribological properties compared with LDPE and HDPE, so that the mixing of UHMWPE with other PE types decreases indicated properties. In addition, specific applications e.g., in the biomedical field require reinforcement using pure polymer: for instance, only pure UHMWPE is allowed for total joint replacements. Thus, the concept of pure polymer reinforcement is more attractive for medical and other applications.

Furthermore, it is important to compare mechanical properties of studied SRCs with other materials and their classes. For this reason, the logarithmic plot of specific stiffness versus specific strength is shown in Figure 1 to compare SRC based on UHMWPE fibers with other materials.

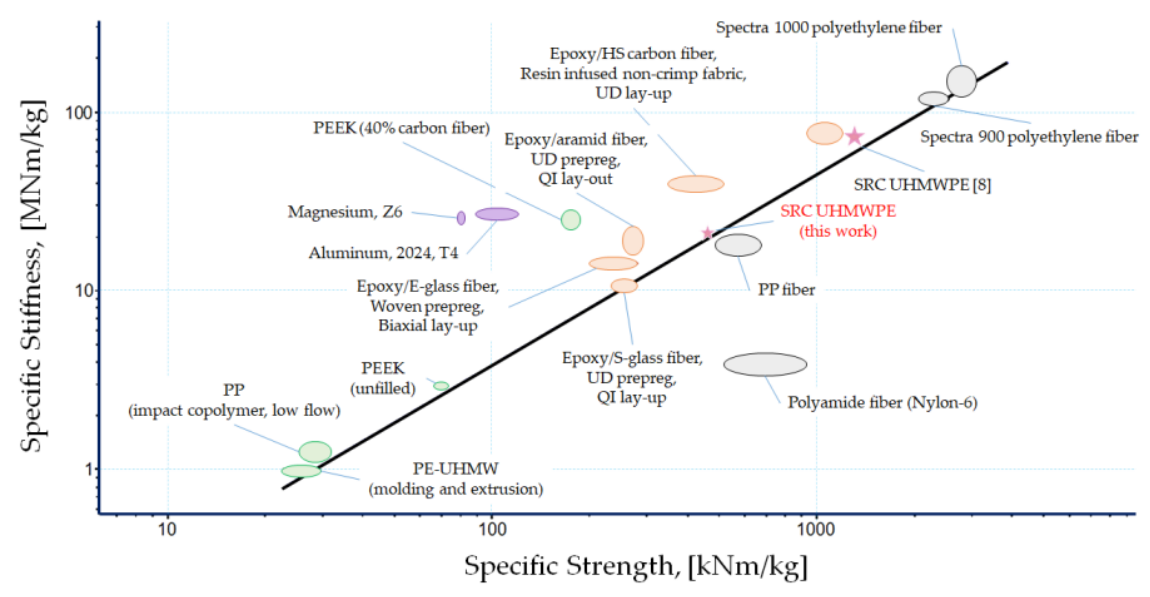

Figure 1. Ashby plot for various materials illustrating the range in specific strength and specific stiffness [15].

As evident from Figure 1, very few polymer-based composite materials can demonstrate the mechanical performance exceeding that of UHMWPE SRC's studied in [1]. For 
example, unidirectional and biaxial composites made from epoxy resin and carbon fibers show superior specific strength compared to the SRC studied here - but not a combination of specific strength and specific stiffness. However, carbon fiber composites are difficult to recycle and cannot be used for medical applications. Another PE/PE composite found in Figure 1 was made by alternation of UHMWPE fibers and HDPE film. This material is also limited in terms of its application and cannot be broadly used after recycling due to the formation of a blend. Other materials are UHMWPE oriented highly crystalline SPECTRATM fibers which cannot be used as bulk material for structural applications. Worth to note that simple rule of mixture is valid for mechanical performance of UHMWPE materials when non-oriented matrix and highly oriented fibers are taken as the constituents of a SRC composite promising further progress for SRCs of optimized structure and fiber content.

SRCs based on UHMWPE manufactured by hot compaction were studied since the end of 1990s and until recently [17-21], and the influence of hot compaction conditions on the properties of SRCs has been reported. However, the processing - structure - properties - performance interrelation that is crucial for performance optimization has not been understood fundamentally. In this article, we address the key issues of UHMWPE-based SRC manufacturing by reporting the data on morphology, crystallinity, and Herman's orientation factor determined by Wide-Angle X-Ray Scattering (WAXS), X-Ray tomography, polarized Raman spectroscopy, Scanning Electron Microscopy (SEM) methods and in situ tensile testing for quantitative evaluation of the impact of hot compaction conditions on the molecular orientation and properties.

\section{Materials and Methods}

\subsection{Self-Reinforced Composite (SRC) Preparartion}

UHMWPE fibers from SGX (DSM Dyneema, Heerlen, Netherlands) with the average diameter of about 15-20 $\mu \mathrm{m}$ and a linear density of 220 dtex were used for the preparation of the SRCs. Hot compaction was used for producing rectangular samples with dimensions of $80 \times 10 \times 2 \mathrm{~mm}^{3}$. The initial fibers were wound unidirectionally between two fixed bobbins that were subsequently removed, and the wound fibers placed into the mold for hot compaction.

SRC samples were manufactured by hot compaction with a heating time of 50 minutes and molding time of 10 minutes followed by cooling in the mold to room temperature at molding pressure. The surface of each fiber undergoes partial melting during hot compaction followed by UHMWPE re-solidification during cooling to form SRC matrix as illustrated in Figure 2. Samples were manufactured at temperatures of $145^{\circ} \mathrm{C}$, $155^{\circ} \mathrm{C}$ or $165^{\circ} \mathrm{C}$ to determine the dependence of structure on processing temperature. Different pressures of $25 \mathrm{MPa}$ and $50 \mathrm{MPa}$ were applied to determine the influence of this processing parameter on the SRC structure. In addition to standard conditions, hot compaction was carried out at two regimes: Regime 1 - 10 minutes at a certain molding pressure and temperature; Regime 2 - 8 minutes at molding pressure, then 2 min of release of molding pressure down to ambient pressure, then return to molding pressure for immediate start of cooling. According to the Clausius-Clapeyron relation [21], elevated pressure shifts the melting temperature to a higher value. Conversely, pressure reduction promotes fiber melting.

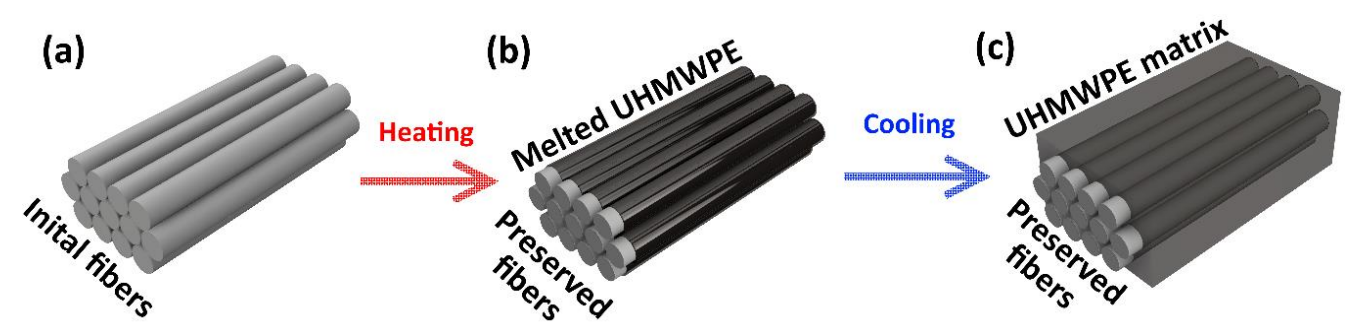


Figure 2. Schematic diagram of the self-reinforced composite (SRC) preparation: (a) initial fiber with winding, (b) molten fibers during hot compaction, and (c) the resulting self-reinforced composite.

\subsection{Scanning Electron Microscopy (SEM) Characterization}

Composite structural studies were conducted using JEOL JSM-6610LV SEM in the secondary electron (SE) imaging mode. The cross-sectional sample surfaces were prepared by cutting followed by polishing. After that, prepared samples were chemically etched to achieve contrast between molten and re-solidified UHMWPE and the unmodified fibers. The etching mixture contained one volume orthophosphoric acid per two volumes of sulfuric acid and $2 \% \mathrm{wt}$./vol. potassium permanganate [22]. Etching was carried out during 4 hours under room conditions using orbital shaker. The etched surfaces were not treated by sputter coating, but SEM imaging was performed at the voltage of $15 \mathrm{keV}$ under low vacuum conditions of 30-50 Pa chamber pressure and electron gun pressure not exceeding $5 \times 10^{-2} \mathrm{~Pa}$, respectively.

Histograms of the fiber cross-sectional size were calculated from obtained SEM images of samples manufactured using ImageJ software by employing the following approach: filtering $\rightarrow$ segmentation $\rightarrow$ statistics extraction. The median filter with a radius of 2.0 pixels was applied as a preprocessing step. Next, the morphological segmentation of the ImageJ plugin was used for fibers separation. Finally, the essential statistics like area and perimeter were extracted by analyzing the particles tool of the ImageJ. The example of applying the described technique to the SEM image is shown in Figure 3. The resulting histograms are shown and discussed in the next section.

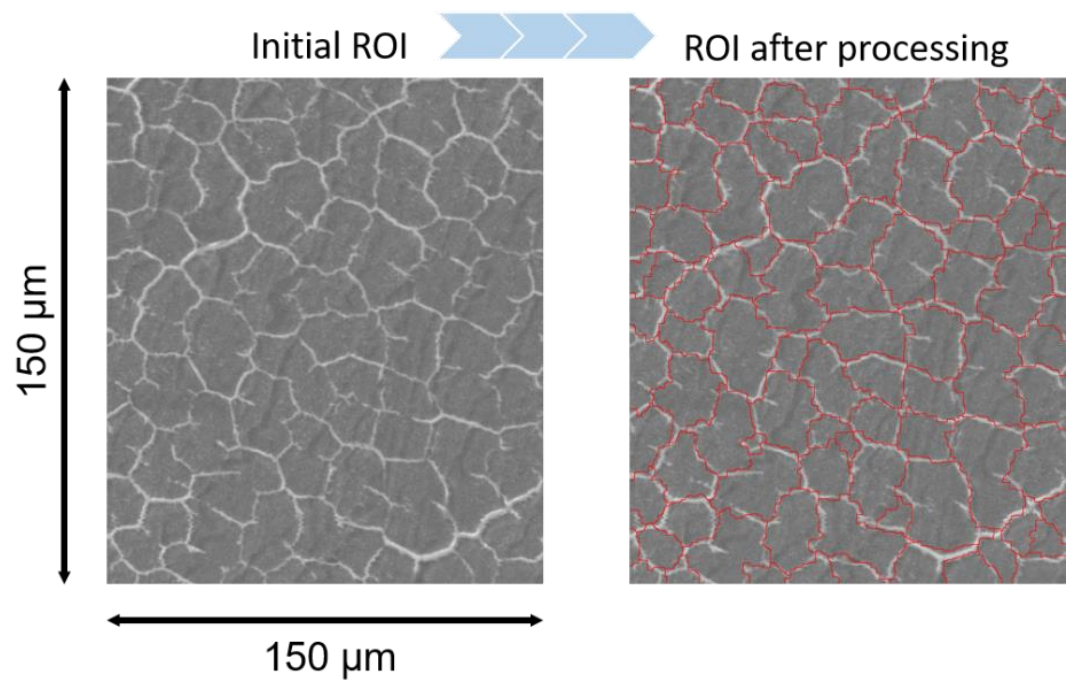

Figure 3. The result of applying the image processing technique for the SEM image of SRC by the ImageJ software.

\subsection{Wide-Angle X-ray Scattering (WAXS) Analysis}

WAXS in transmission mode was carried out to determine crystallinity ratio and crystalline chains orientation as a function of hot compaction conditions. Parabolic multilayer mirror (Osmic) X-ray optics were used together with a cylindrical capillary. The selected radiation wavelength was $\mathrm{Cu} \mathrm{K}_{\alpha 1}(\lambda=0.154 \mathrm{~nm})$ generated using the voltage and current of $30 \mathrm{kV}$ and $40 \mathrm{~mA}$, respectively. The beam was collimated to the diameter of approximately $200 \mu \mathrm{m}$. 2D WAXS patterns were obtained with a sample to detector distance of $75 \mathrm{~mm}$ using a photosensitive image plate detector (FUJIFILM) then read by a BASF 5000 scanner.

Considering the fiber cross-sectional size of $\sim 15 \mu \mathrm{m}$, the signal collected corresponded to the average from the composite material, rather than its individual constituents. Herman's factor $f$ that is most often used to estimate the orientation of crystallites or molecules was calculated as a function of orientation for each determined lattice plane of each sample according to equation (1) below. This value allows describing the orien- 
tation degree of objects of interest (for example, a normal of a crystallographic plane) relative to a chosen direction (for example, a fiber axis).

$$
f=1 / 2\left(3<\cos ^{2} \alpha_{(h k l, z)}>-1\right)
$$

where $<\cos ^{2} \alpha_{(n k l, z)}>$ can be calculated as:

$$
<\cos ^{2} \alpha_{(h k l, z)}>=\frac{\int_{0}^{\frac{\pi}{2}} I(\alpha, \theta) \cdot \sin \alpha_{(h k l, z)} \cdot \cos ^{2} \alpha_{(h k l, z)} d \alpha}{\int_{0}^{\frac{\pi}{2}} I(\alpha, \theta) \cdot \sin \alpha_{(h k l, z)} d \alpha},
$$

and $I(\alpha, \theta)$ is the scattering intensity as a function of the azimuthal angle $\alpha$ and Bragg angle $\theta$ [23].

\subsection{In situ Tensile Test}

The prepared samples were tested using a universal portable device as Deben Microtest $1 \mathrm{kN}$ Tensile Stage (Deben UK Ltd., London, UK) in situ inside the chamber of the SEM Tescan Vega 3 (Tescan Orsay Holding, Brno, Czech Republic) in tensile mode. The illustration of the experiment is shown in Figure 4. Moreover, specimens with fiber winding in the transverse direction were sprayed with a thin Au layer about $5 \mu \mathrm{m}$ to remove typical polymer charging during the SEM session. In contrast, samples with longitudinal to fiber direction were checked on air under room temperature. The indicated devices (SEM \& Deben Microtest) were synchronized. The regime of the tests was as follows: (Backscattered-Electron) BSE imaging type, low vacuum mode at $10 \mathrm{~Pa}$, resolution scan regime, HV $25 \mathrm{kV}$, magnification x34, a field of view $6144 \mu \mathrm{m}$, speed scan 4 (3.20 $\mu \mathrm{s} /$ pixel), focus depth $2.940 \mathrm{~mm}$ for the SEM, and a permanent crosshead speed of 0.5 $\mathrm{mm} / \mathrm{min}$ for Deben Microtest, respectively. To provide essential features on the sample's surface for Digital Image Correlation (DIC) analysis, a glue containing Ag nanoparticles was used. The sequences of $\sim 25$ images were put into Matlab-based comprehensive and robust Ncorr program [24] and processed with the subset radius 29, subset space 2, and the number of threads 4 . Video recordings of tensile tests were prepared for each specimen and uploaded as Supplementary Material with labels of the kind "Video S1-S4", etc.

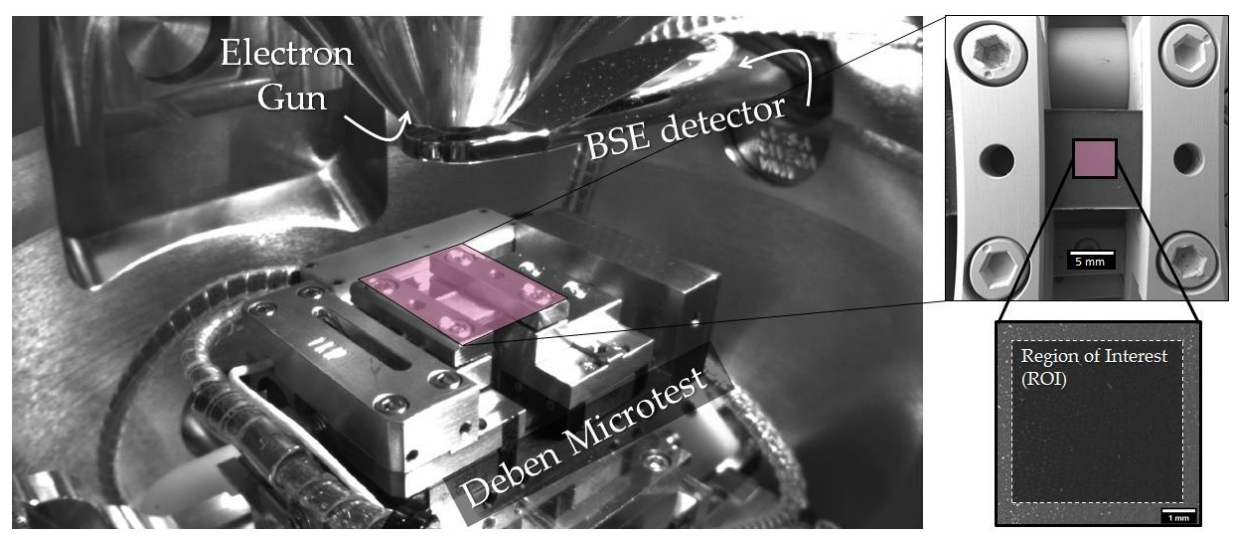

Figure 4. The typical illustration of in situ tensile test with the used Region of Interest (ROI) for DIC analysis.

\subsection{Raman Spectroscopy Measurements}

Raman spectroscopy measurements were carried out to reveal the SRC anisotropy and to determine qualitatively the influence of hot compaction conditions on the SRC structure. Raman spectra were collected at room temperature using DXR2xi Raman Imaging Microscope (Thermo Fisher Scientific, MA, USA). The excitation source used was a monochromatic green line emitted by an Ar ion laser at a wavelength of $532 \mathrm{~nm}$ with a power of $10 \mathrm{~mW}$ and slit width of $50 \mu \mathrm{m}$. The SRC spectra were acquired by 200 scans for $0.1 \mathrm{~s}$ exposure time for each scan in the back-scattering geometry. Considering the beam 
spot diameter of $1 \mathrm{~mm}$ and fiber diameter of $25 \mu \mathrm{m}$, the averaged Raman scattering was obtained from the matrix phase and the reinforcing element, i.e., from the entire material.

Raman measurements for each sample were made at two positions of the initial beam polarization relative to the sample without using a polarizer for the response signal. In the first position, the polarization of the laser was parallel to the direction of the fibers in the sample $\left(\psi=0^{\circ}\right)$ as shown in Figure 5. The other measurements were carried out with the polarization plane perpendicular to the axis of the sample $\left(\psi=90^{\circ}\right)$.

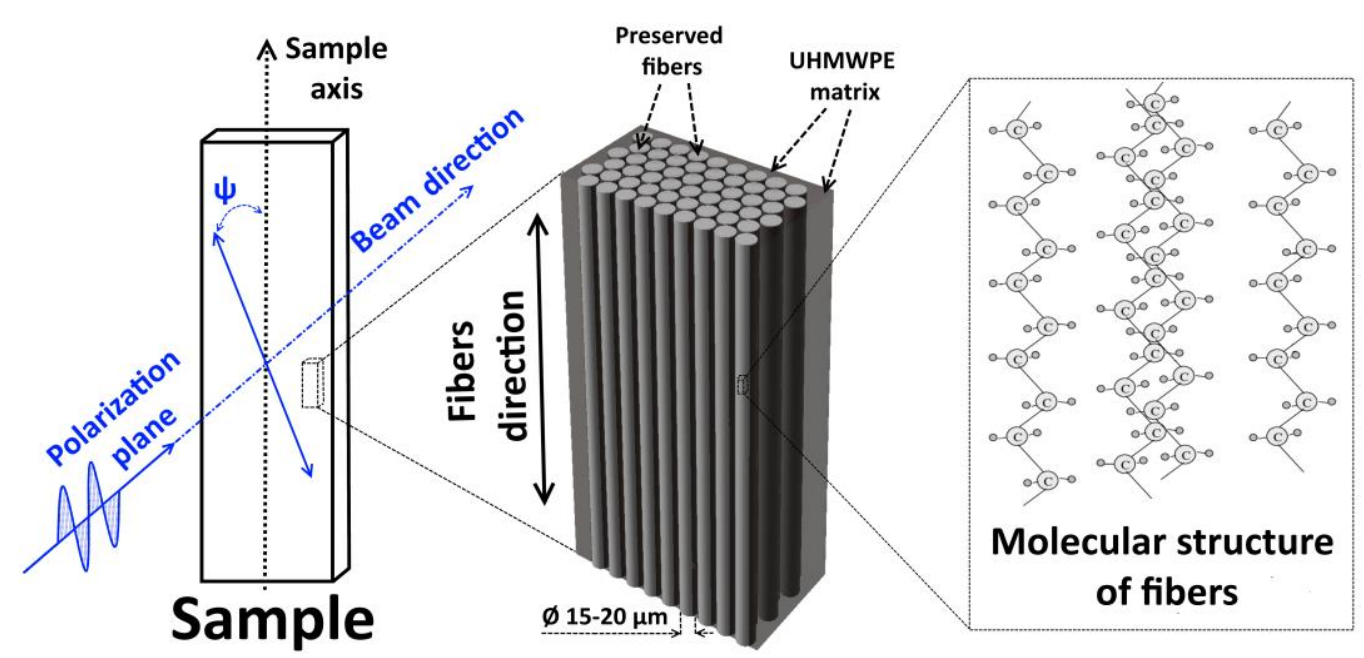

Figure 5. Position of the initial beam polarization relative to the sample, fibers and molecules.

\subsection{X-ray Tomography Analysis}

X-ray micro-computed tomography $(\mu \mathrm{CT})$ measurements were carried out to prove absence of pores and to show the structure uniformity. Phoenix Nanotom X-ray $\mu C T$ facility was used to characterize the morphology. Rectangular specimens with $8 \times 2 \times 2 \mathrm{~mm}^{3}$ in size were characterized with a resolution of $1 \mu \mathrm{m}$. The $\mu \mathrm{CT}$ procedure was based on the acquisition of a series of X-ray radiographs of a sample that was rotated step by step around a vertical axis perpendicular to the incident $X$-ray beam with the use of a copper filter. A mathematical algorithm was used to reconstruct the internal 3D volume structure of the samples. The final resolution of the 3D-images was achieved to reach voxels of dimensions $2 \times 2 \times 2 \mu \mathrm{m}^{3}$. Finally, to visualize and check the integrity of the structure for obtained datasets, Avizo software was used.

\section{Results and discussion}

\subsection{WAXS Analysis}

SRC samples obtained at temperatures of $145^{\circ} \mathrm{C}, 155^{\circ} \mathrm{C}$, or $165^{\circ} \mathrm{C}$ and pressures of $25 \mathrm{MPa}$ or $50 \mathrm{MPa}$ in both molding regimes during hot pressing were selected for WAXS characterization. Diffraction signal was acquired using photosensitive film, which accumulates X-ray signals diffracted from crystallographic planes. Exposure of about 15 hours was applied to acquire 2D diffraction patterns of optimal quality (the intensity of the white color is proportional to the accumulated diffracted X-ray signal), which are shown for example in Figure 6. 


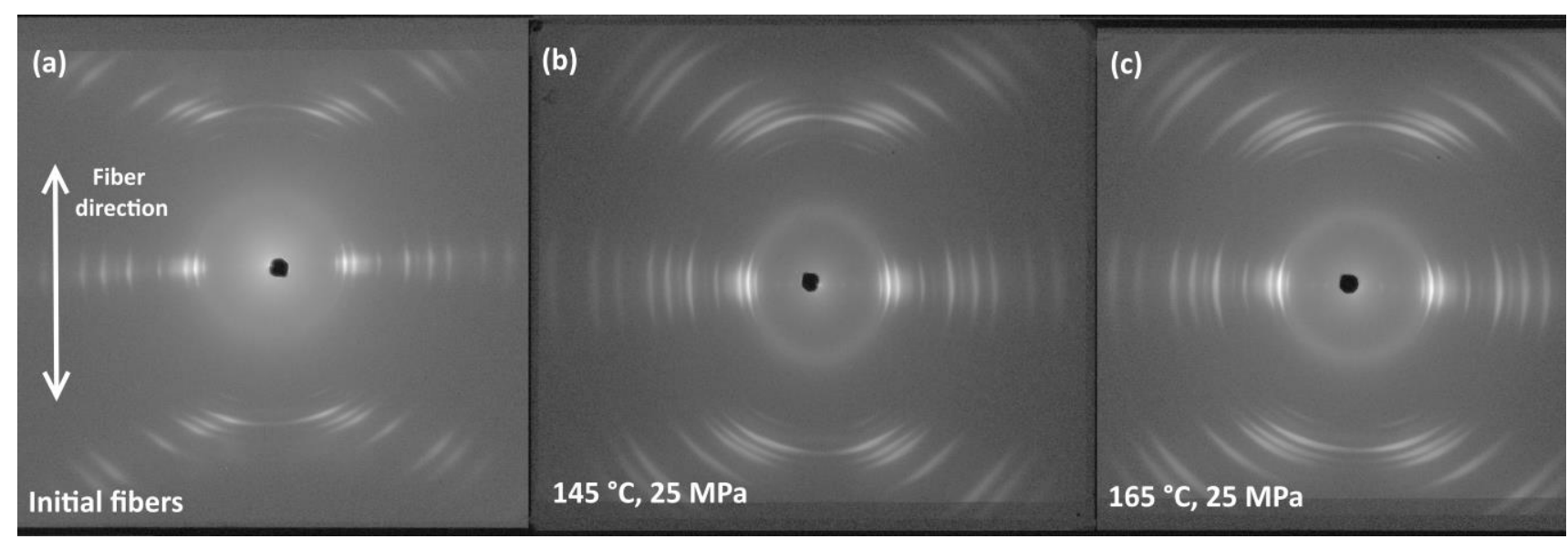

Figure 6. 2D WAXS patterns of (a) the pristine fibers and samples made at $25 \mathrm{MPa}$ and (b) $145^{\circ} \mathrm{C}$ and (c) $165^{\circ} \mathrm{C}($ Regime $1)$.

Figure 6(a) demonstrates short and narrow segments of Debye rings corresponding to certain crystallographic planes of the orthorhombic O-phase. This manifests a number of features characteristic to the obtained UHMWPE SRCs: a) high crystallinity; b) predominant orientation of fibers along crystallographic directions and c) high perfectness of crystalline phase. It also can be seen in the Figures 6(b-c) that pattern segments tend to become longer and wider at higher compaction temperatures reflecting more pronounced melting that causes the misorientation of crystallites and perhaps the accumulation of defects.

1D diffraction patterns were extracted from 2D diffraction patterns for detailed analysis for $0^{\circ}$ and $90^{\circ}$ angles in respect to the main fiber axis as shown in the Figure 7(a). The extraction process involved symmetric sectors averaging (e.g., $0^{\circ}$ and $180^{\circ}$ ) with a range from -5 to 5 degrees for two perpendicular directions. The intensity of $X$-ray peaks in $0-180^{\circ}$ direction is clearly much weaker than in $90-270^{\circ}$ direction. Further, the analysis was carried out for 1D X-ray diffraction spectra detected along $90^{\circ}$ direction.

As demonstrated in the Figure 7(b) almost no amorphous halo is revealed in the 1D X-ray diffraction spectra proving high degree of crystallinity in the studied SRC samples. An $1 D$ spectrum contains a low intensity peak at approximately $2 \theta \approx 19.3^{\circ}$ (corresponds to (010) reflection of monoclinic crystalline M-phase) and strong peaks at approximately $2 \theta \approx 21.5^{\circ}$ and $24.1^{\circ}$ (correspond to the reflections (110) and (200) of orthorhombic crystalline O-phase, respectively). Therefore, SRCs consists of mainly stable orthorhombic UHMWPE phase, and it also contains a small amount of metastable monoclinic phase that forms during the manufacture of fibers.
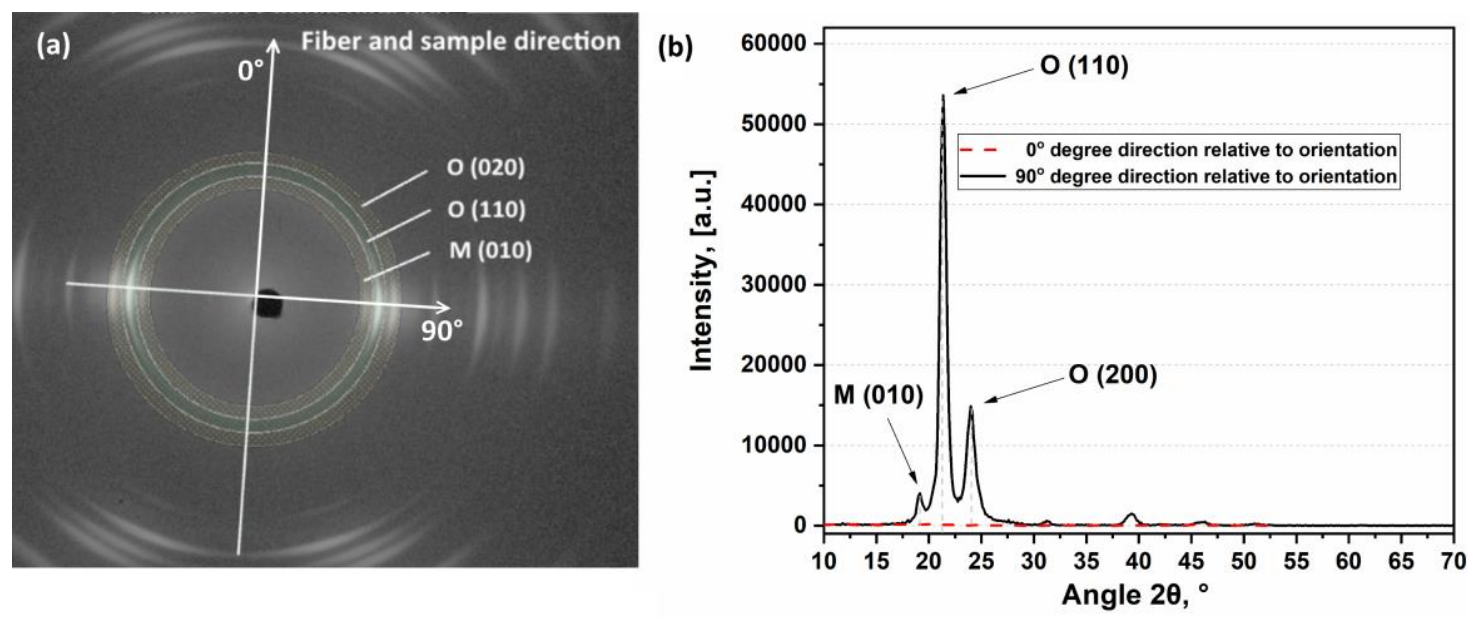

Figure 7. (a) 2D diffraction pattern and (b) $1 \mathrm{D}$ profile derived from $2 \mathrm{D}$ diffraction pattern - sample prepared at $145^{\circ} \mathrm{C}$ and $25 \mathrm{MPa}$ (Regime 2). 
Processing of digital images [25] makes possible to analyze the variation of peak intensity with orientation angle over radial intensity distribution as exemplified in the Figure 8(a) for each crystallographic plane of SRCs obtained at $145{ }^{\circ} \mathrm{C}$ and $25 \mathrm{MPa}(\operatorname{Re}-$ gime 1). The diffraction patterns appear in planes that are perpendicular to the indicated crystallographic planes. Thus, these signals form $90^{\circ}$ with crystallographic planes. The strongest intensity of the main peaks was achieved in the vicinity of orientation angle of $90^{\circ}$ and $270^{\circ}$ for both $\mathrm{O}-$ and M-phases proving predominant orientation of crystallographic planes, crystallites and crystalline molecular chains along the fibers' (and sample as prepared) principal axis.
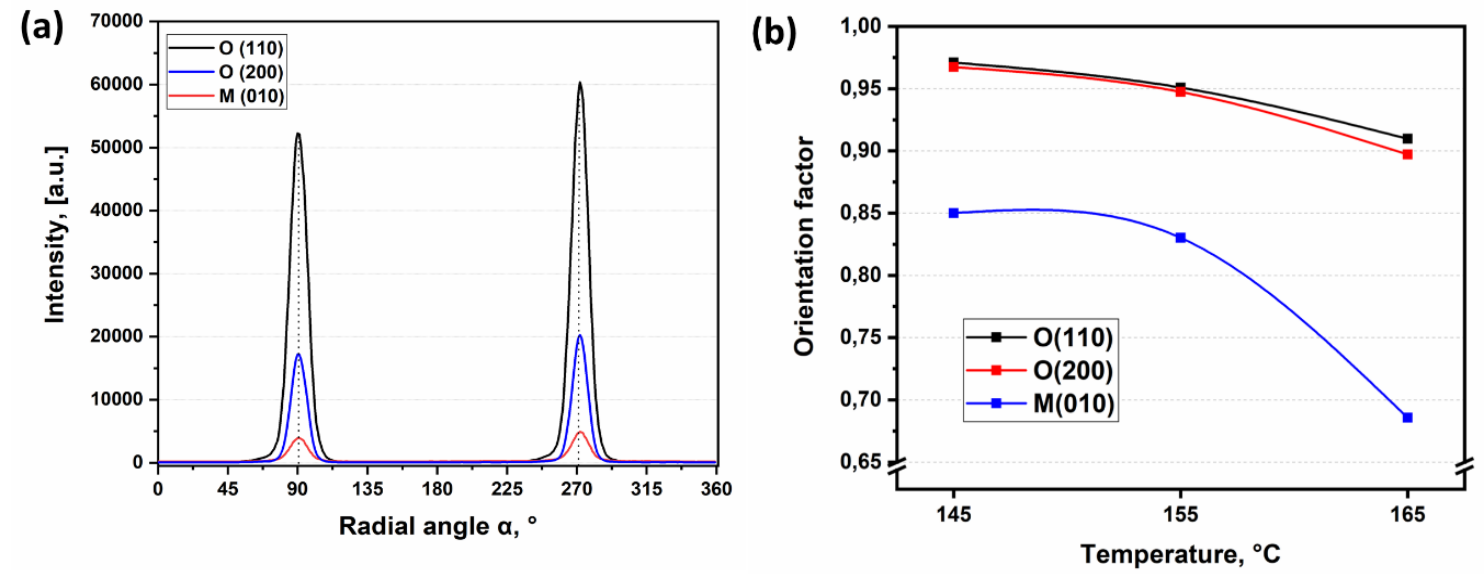

Figure 8. Radial intensity distribution for a composite obtained at $145^{\circ} \mathrm{C}$ and $25 \mathrm{MPa}$ (Regime 1) (a) and Herman's factor (b) for a composite obtained at different temperatures and $25 \mathrm{MPa}$ (Regime 1).

The $\left\langle\cos ^{2} \alpha_{(h k l, z)}\right\rangle$ average cosine was calculated for the studied samples in accordance with equation (2) for each crystallographic plane, where $\alpha$ is the azimuthal angle between the sample axis and each detected plane considering $90^{\circ}$ between the normals to planes and these planes. The values of Herman's orientation factor $f$ calculated using equation (1) for each crystallographic plane for all SRC samples are given in Table 1 .

Table 1. Herman's factor $f$ for crystallographic planes for SRCs obtained at different conditions.

\begin{tabular}{|c|c|c|c|c|c|c|}
\hline \multicolumn{7}{|c|}{ Regime 1} \\
\hline \multirow{2}{*}{$\mathrm{T},{ }^{\circ} \mathrm{C}$} & \multicolumn{3}{|c|}{$25 \mathrm{MPa}$} & \multicolumn{3}{|c|}{$50 \mathrm{MPa}$} \\
\hline & $\mathrm{O}(110)$ & O (200) & M (010) & $\mathrm{O}(110)$ & O (200) & M (010) \\
\hline $145^{\circ} \mathrm{C}$ & 0.971 & 0.968 & 0.869 & 0.97512 & 0.97242 & 0.877 \\
\hline $155^{\circ} \mathrm{C}$ & 0.960 & 0.957 & 0.859 & 0.96178 & 0.95786 & 0.863 \\
\hline $165^{\circ} \mathrm{C}$ & 0.960 & 0.954 & 0.856 & 0.96097 & 0.95671 & 0.859 \\
\hline \multicolumn{7}{|c|}{ Regime 2} \\
\hline \multirow{2}{*}{$\mathrm{T},{ }^{\circ} \mathrm{C}$} & \multicolumn{3}{|c|}{$25 \mathrm{MPa}$} & \multicolumn{3}{|c|}{$50 \mathrm{MPa}$} \\
\hline & O (110) & O (200) & M (010) & O (110) & O (200) & M (010) \\
\hline $145^{\circ} \mathrm{C}$ & 0.971 & 0.967 & 0.850 & 0.971 & 0.969 & 0.852 \\
\hline $155^{\circ} \mathrm{C}$ & 0.950 & 0.947 & 0.830 & 0.958 & 0.952 & 0.837 \\
\hline $165^{\circ} \mathrm{C}$ & 0.909 & 0.897 & 0.685 & 0.952 & 0.950 & 0.778 \\
\hline
\end{tabular}


As it seen from Table 1, Herman's factors for both crystallographic planes in major O-phase are close to 1 revealing (a) a high degree of crystalline molecular chains orientation along the fiber axis and (b) almost no dependence of degree of orientation on temperature or pressure when hot compaction is carried out at Regime 1. Minor M-phase is less oriented and behaves similarly at compaction Regime 2. Under these conditions the high degree of orientation of crystallites is preserved in UHMWPE SRCs even after hot compaction.

Herman's factor turns out to be sensitive to temperature at lower compaction pressure $25 \mathrm{MPa}$ demonstrating lower degree of orientation at higher compaction temperature. We interpret these data as the evidence of more pronounced melting and, as a result, better structural integrity due to the formation of matrix phase with lower degree of orientation than for the pristine fibers. The pressure release causes greater misorientation in SRCs in comparison with those obtained at constant molding pressure. Pressure release gives greater mobility to long polymer chains and through this more chances for intense amorphization of fiber surface at melting i.e., the formation of less oriented matrix.

In contrast, the elevated pressure allows preserving the orientation of crystallites and crystalline molecular chains due to the less intense melting of pristine fibers. This interpretation was supported by the data from differential scanning calorimetry [20]. Overall, elevated temperature as well as pressure release result in the decrease of degree of orientation and, highly likely, in poorer mechanical performance.

\subsection{Mechanical perfomance}

The specimens with fibers oriented longitudinally and transversely in respect of tension axis were tested to study the influence of hot compaction conditions on mechanical performance of SRC. The data on ultimate tensile strength (UTS) are presented in Table 2. The UTS long in longitudinal direction scaled from $67.8 \mathrm{MPa}$ to $174 \mathrm{MPa}$ with the increase of compaction temperature from $145^{\circ} \mathrm{C}$ to $155^{\circ} \mathrm{C}$ that is believed to be caused by the increment of matrix volume, providing better load transfer to the reinforcing fibers. However, further increase of compaction temperature up to $165{ }^{\circ} \mathrm{C}$ led to decrease in strength down to $142.3 \mathrm{MPa}$ due to the smaller ratio of fiber-to-matrix volumes. In contrast, UTS trans in the transverse direction gradually grows from $4.1 \mathrm{MPa}$ to $16.5 \mathrm{MPa}$ with compaction temperature enhancing the volume fraction of isotropic molten PE matrix, since the mechanical load is transferred through the matrix when a unidirectional composite is extended in the transverse direction. Similar tendency for both directions was observed for unidirectional PE-based SRCs at bending test [21].

Table 2. Ultimate Tensile strength of SRCs in longitudinal and transverse directions.

\begin{tabular}{ccccc}
\hline \multicolumn{2}{c}{ Conditions } & & UTS & \\
\cline { 1 - 4 } $\mathbf{T},{ }^{\circ} \mathrm{C}$ & Pressure & MPa & UTS \\
\hline $145^{\circ} \mathrm{C}$ & $25 \mathrm{MPa}$ & Regime & MPa \\
\hline $155^{\circ} \mathrm{C}$ & $25 \mathrm{MPa}$ & 1 & 67.8 & 4.1 \\
\hline $155^{\circ} \mathrm{C}$ & $25 \mathrm{MPa}$ & 1 & 174.3 & 7.7 \\
\hline $165^{\circ} \mathrm{C}$ & $25 \mathrm{MPa}$ & 2 & 164.7 & 8.3 \\
\hline $155^{\circ} \mathrm{C}$ & $50 \mathrm{MPa}$ & 1 & 142.3 & 16.5 \\
\hline
\end{tabular}

As expected, according to the Clausius-Clapeyron relation [26], elevated hot compaction pressure (50 MPa against $25 \mathrm{MPa}$ ) resulted in lower matrix content and, therefore, poorer UTS in both longitudinal and transverse directions for samples obtained at $155^{\circ} \mathrm{C}$, with UTS long dropping from 174.3 MPa to $129.5 \mathrm{MPa}$ (by $-25,7 \%$ ), and UTS trans by $-44,1 \%$. On the other hand, pressure release seems to promote UTS trans - that is slightly increased from 7.7 $\mathrm{MPa}$ to 8.3 MPa. These facts are explained by more pronounced 
melting during hot compaction at pressure release that is also proven by WAXS analysis showing large misorientation for samples obtained with pressure release.

A series of transverse fiber winding specimens for SEM in situ tensile testing was fabricated under following conditions: molding temperature 150, 160, and $170{ }^{\circ} \mathrm{C}$; molding pressure 25 (and $50 \mathrm{MPa}$ for $160^{\circ} \mathrm{C}$ ). The results showed the same trends as described above. The loading curves for this series are represented in Figure 9.

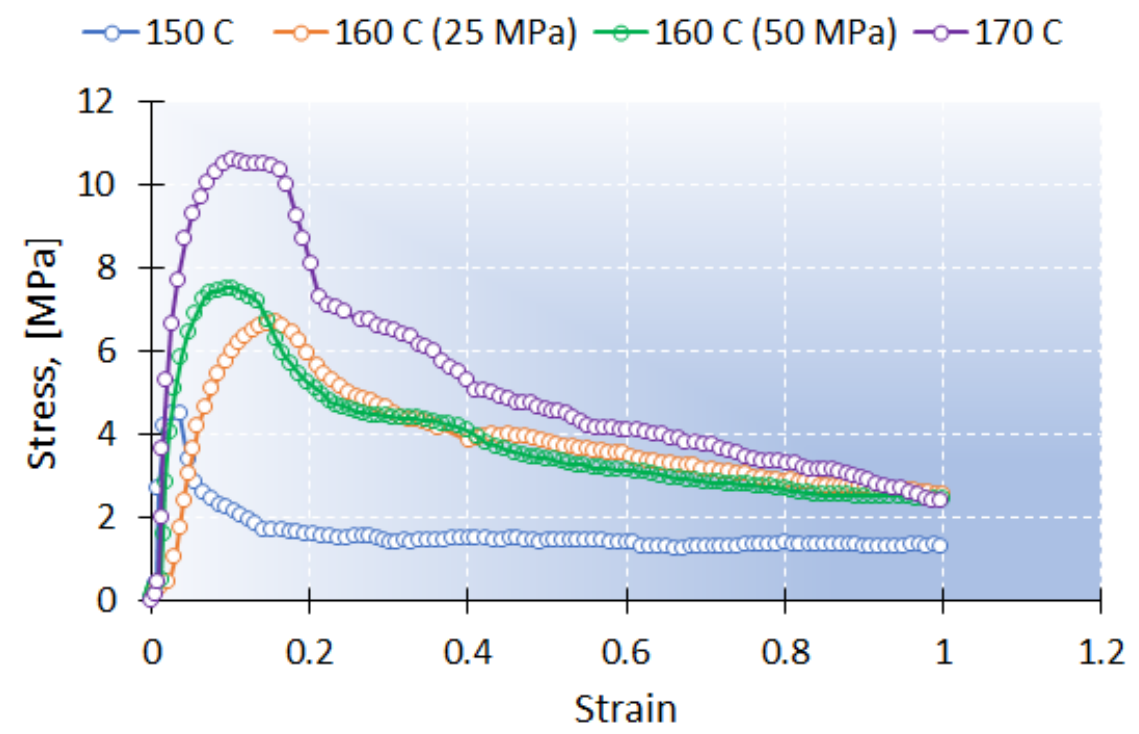

Figure 9. The loading curves for transverse fiber winding samples (molding temperature 150,160 , and $170{ }^{\circ} \mathrm{C}$, molding pressure: 25 and $50 \mathrm{MPa}$ ).

DIC analysis reveals significant strain localization in the middle of ROI. Video recordings (Figures S1-S4) illustrate the character of structural damage and disintegration through fiber separation process (Figure 10).

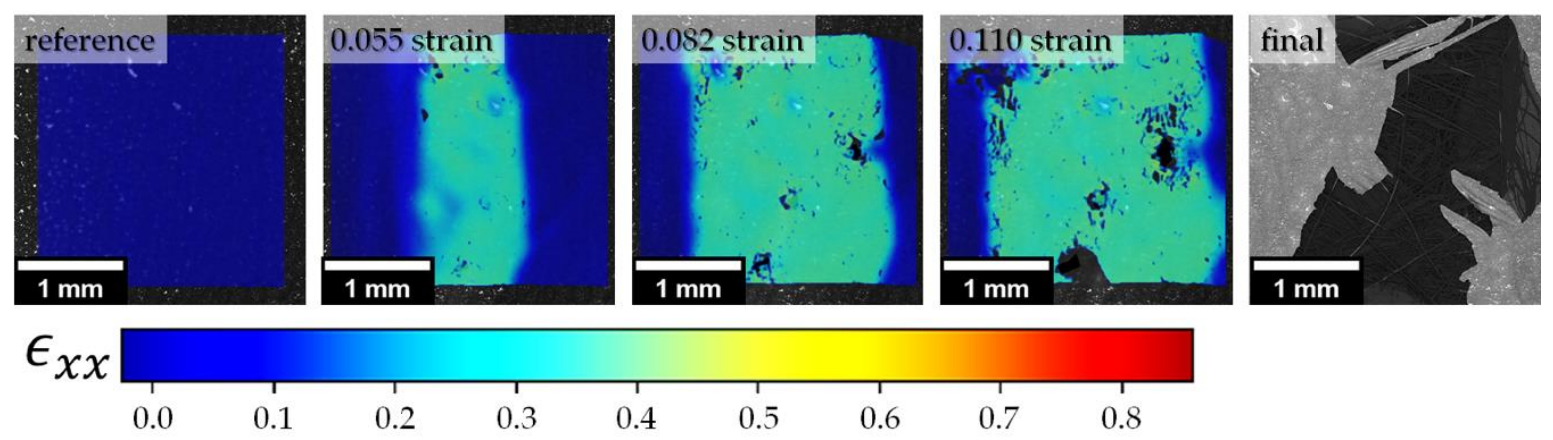

Figure 10. Typical strain localization and structure fluffiness observed by DIC and SEM, respectively, during in situ tensile test of SRCs with transverse fiber winding.

\subsection{SEM Characterization}

Cross sections of SRCs compacted at $150{ }^{\circ} \mathrm{C}, 160^{\circ} \mathrm{C}$, and $170{ }^{\circ} \mathrm{C}(25 \mathrm{MPa})$ at Regime 1 are shown in Figure 11. The creation of relatively uniform monolithic structure is seen clearly, with fiber bonding via the formation of narrow interfiber matrix layer consisting of recrystallized molten polymer. Since the etching agent applied preferentially attacks amorphous isotropic UHMWPE, its location is revealed by the etching grooves Therefore, it is concluded that only fiber surface experiences melting during hot compaction. Furthermore, the core regions of fibers are deformed to become polygonal at 
high pressure. It can also be assumed that the thickness of etched grooves correlates with the matrix volume fraction gradually increasing with compaction temperature.
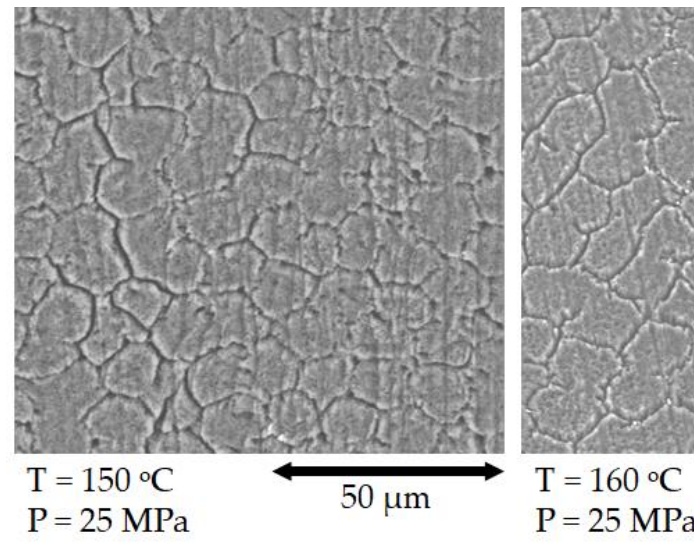

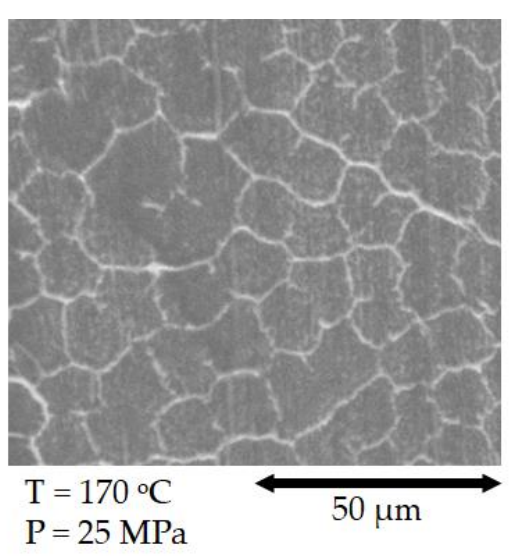

Figure 11. Cross section of samples obtained $150{ }^{\circ} \mathrm{C}, 160^{\circ} \mathrm{C}, 170{ }^{\circ} \mathrm{C}(25 \mathrm{MPa})$ (Regime 1$)$.

Statistical parameters for achieved cross-sections such as fiber size distribution for samples with different process conditions are shown in Figure 12. It should be mentioned that distributions were plotted for samples prepared under constant pressure. The analysis gave mean fiber sizes of 10,20 , and $24 \mu \mathrm{m}$ for 150,160 , and $170{ }^{\circ} \mathrm{C}$, respectively. The histogram obtained for the structure prepared at $150{ }^{\circ} \mathrm{C}$ has a lognormal distribution, while other plots do not reveal statistical significance for commonly anticipated distributions like normal of lognormal.

$=170 \mathrm{C}, 25 \mathrm{MPa}=160 \mathrm{C}, 25 \mathrm{MPa}=150 \mathrm{C}, 25 \mathrm{MPa}$

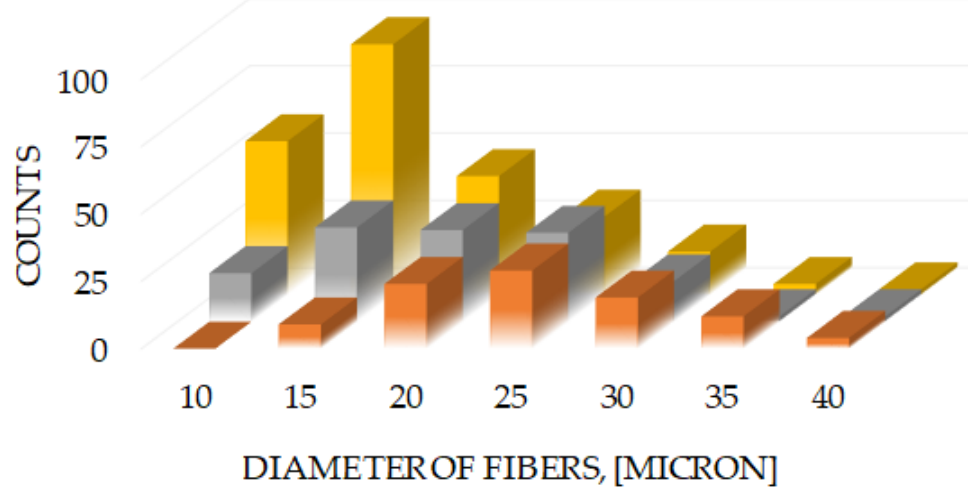

Figure 12. The histograms of fiber size distributions for samples with different preparation conditions.

\subsection{Raman spectral analysis}

Raman spectroscopy measurements were carried out to assess qualitatively the anisotropy of SRC samples. The degree of orientation can be evaluated with change in peak intensity with rotation of the polarizer angle relatively to the sample axis [27-28]. Raman spectra of SRC samples obtained at $165^{\circ} \mathrm{C}$ and $25 \mathrm{MPa}$ or $50 \mathrm{MPa}$ (Regime 1 ) at $0^{\circ}$ and $90^{\circ}$ between the SRC axis and initial beam polarization are depicted in the Figure 13. For all samples, peaks at $1130 \mathrm{~cm}^{-1}$ (C-C stretching bonds) and $1416 \mathrm{~cm}^{-1}\left(-\mathrm{CH}_{2}-\right.$ bending vibrations in crystalline phase) became lower when the polarization angle changed from $0^{\circ}$ to $90^{\circ}$. This is caused by the parallelism of the c-axis of UHMWPE orthorhombic crystallites, which are believed to be collinear to the fibers' axis. A reverse trend is found for the bands at 1440 and $\mathrm{cm}^{-1}$ and $1460 \mathrm{~cm}^{-1}$ which are likely corresponding to $-\mathrm{CH}_{2}$ - bending 
vibrations in amorphous phase. The same result was observed for other types of specimens.

(a)

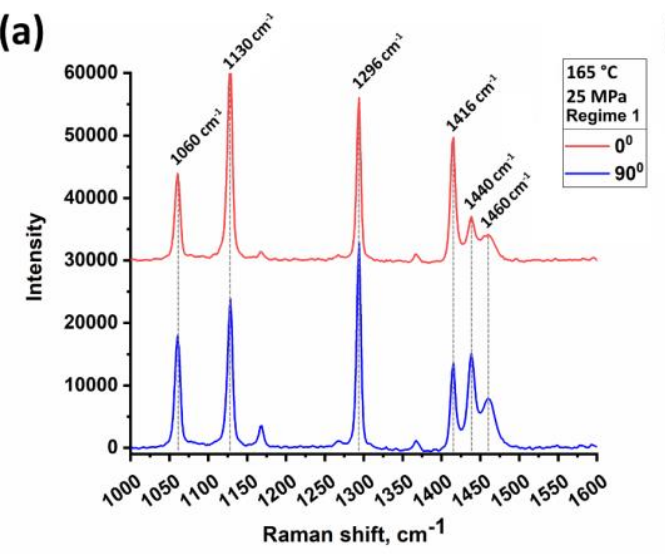

(b)

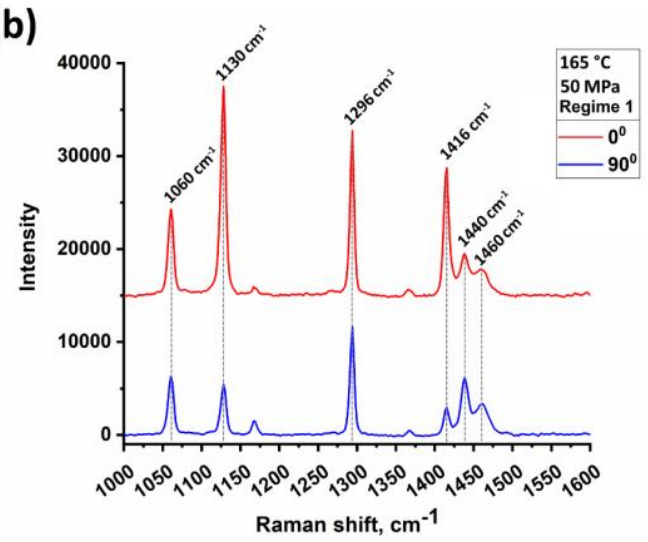

Figure 13. Raman spectra of SRCs obtained at $165^{\circ} \mathrm{C}$ and $25 \mathrm{MPa}(\mathbf{a})$ or $50 \mathrm{MPa}$ (b) (Regime 1) at $0^{\circ}$ (red) and $90^{\circ} \mathrm{C}(\mathrm{blue})$ between the SRC axis and initial beam polarization.

\subsection{X-ray Tomography Analysis}

X-ray tomography was carried out to visualize the possible internal defects (voids, cracks and other imperfections) and general 3D appearance of internal volumes of SRC samples, as represented in Figure 14. It was initially expected that the vanishing difference in density of matrix and reinforcing fibers would not permit to segment these constituents. Indeed, X-ray tomography demonstrates the structural integrity of the entire SRCs composite and, moreover, proves the lack of porosity or interfaces at achieved voxel size. Delamination can be detected in the sample corners where knife sawing, perhaps, detrimentally damages the material crushing more fragile matrix. This type of defects is not formed when gentle cutting with a diamond blade is applied.

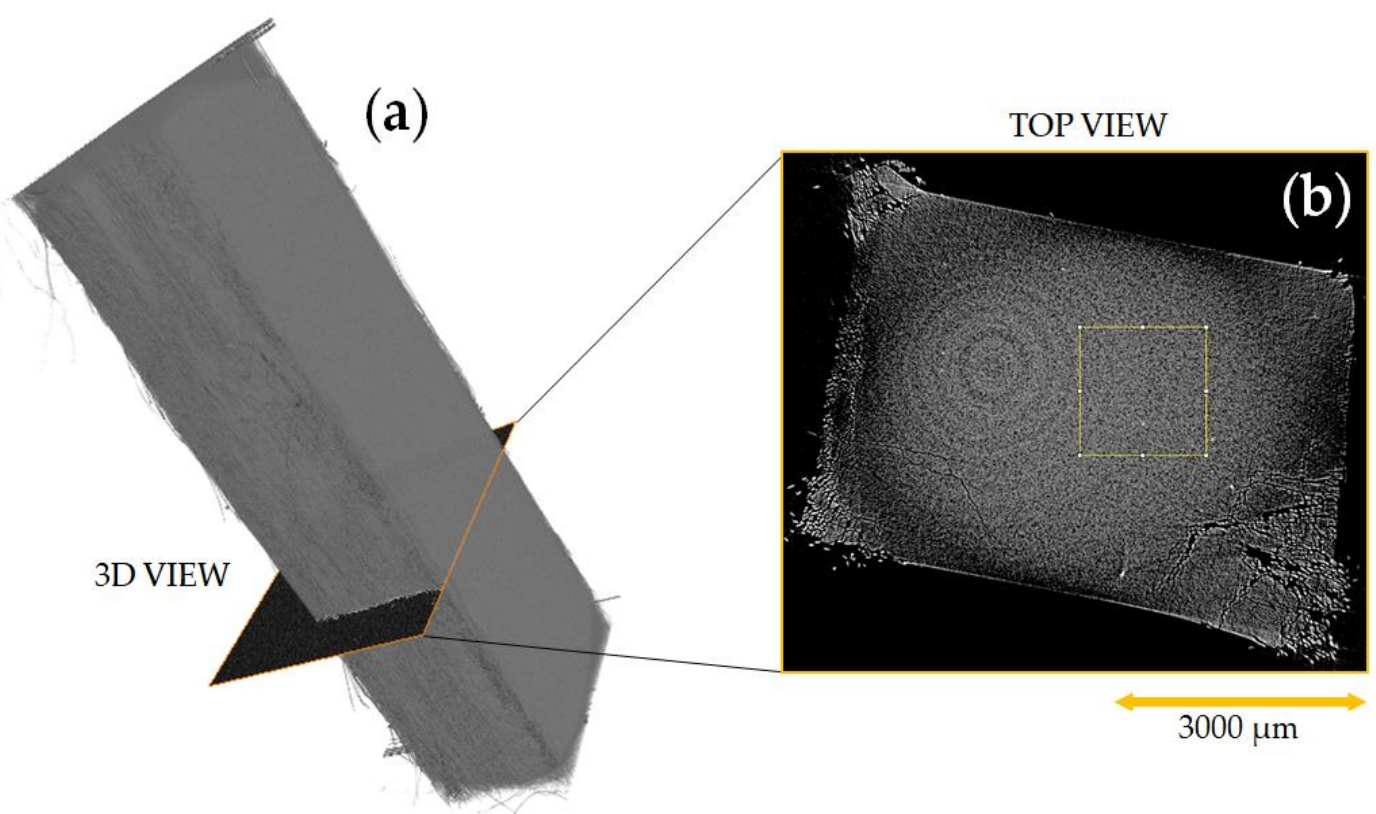

Figure 14. X-ray tomography (a) and cross section (b) for SRC obtained at 165 and $25 \mathrm{MPa}$ (Regime 1).

\section{Conclusions}


Self-reinforced composites fabricated through hot molding of highly crystalline UHMWPE fibers promise the achievement of attractive combination of high mechanical performance, sustainability and chemical resistance applicable in many traditional engineering applications and biomedical devices. Optimization of technological parameters for a material obviously requires thorough structure studying with a variety of traditional and recently developed characterization techniques. This evokes revisiting and reviewing of materials science basics such as undertaken in this research devoted to UHMWPE-based SRCs.

The achieved study showed an almost full spectrum of peculiarities of the self-reinforced composite structures based on UHMWPE manufactured for various preparation conditions that potentially have a wide range of future applications.

In this study, advanced and comprehensive methods like WAXS, X-ray tomography, SEM, mechanical test, Raman spectroscopy with a combination of modern processing tools as Avizo, ImageJ, Ncorr were directed to precisely characterize the inner structure of the self-reinforced composites based on UHMWPE fibers produced for different processing conditions, namely, temperature and pressure, on micro and nanoscale levels. We found that manufactured SRCs have structural integrity without the presence of any other substances or chemical modifications that were observed by X-ray tomography and Raman spectroscopy methods. Besides, WAXS analysis demonstrated that a high degree of orientation of crystallites and crystalline molecular chains along the fiber axis is preserved in UHMWPE SRCs even after hot compaction and the current statement does not depend on the pressure and temperature. Moreover, SEM in situ mechanical tests showed that growth in hot compaction pressure resulted in lower matrix content and poorer longitudinal and transverse tensile strength that corresponds with the Clausius-Clapeyron relation.

To sum up, the optimal process condition of SRC preparation could be chosen as 165 ${ }^{\circ} \mathrm{C}$ under $25 \mathrm{MPa}$. The achieved results set the next investigation plan. For instance, SRCs could withstand carbon fibers and be applied for ballistic as an armor vest or used in medicine as a knee replacement implant due to their biocompatibility. So, it would be attractive to study the planting and winding of fibers' impact on the composite properties and tribological response.

Supplementary Materials: The following are available online at www.mdpi.com/xxx/s1, Figure S1: title, Table S1: title, Video S1: title.

Author Contributions: Conceptualization: D.Z. and D.C.; methodology: D.Z., M.P., A.K., T.D. and I.I.; software: E.S., C.B. T.D. and A.K.; validation: D.Z., D.C. and A.I.; investigation: D.Z., I.R. and M.P.; writing-original draft preparation: D.Z. and E.S.; writing-review and editing: D.Z., D.C., I.R. and A.M.; visualization: D.Z. C.B., E.S., G.S. and I.I.; supervision: D.C. A.I. and I.R.; funding acquisition: D.C. All authors have read and agreed to the published version of the manuscript.

Funding: This work was funded by the Russian Science Foundation (RSF) (project No. 21-73-20205).

Acknowledgments: Authors thank Olivier Ferry and the competence center of IJL (France) for the recording tomography results. G.S. gratefully acknowledges the financial support of the Ministry of Science and Higher Education of the Russian Federation in the framework of Increase Competitiveness Program of MISiS (support project for young research engineers).

\section{References}

1. Capiati, N.J.; Porter, R.S. The concept of one polymer composites modelled with high density polyethylene. J Mater Sci 1975, 10, 1671-1677, doi:10.1007/BF00554928.

2. Karger-Kocsis, J.; Bárány, T. Single-polymer composites (SPCs): Status and future trends. Composites Science and Technology 2014, 92, 77-94, doi:10.1016/j.compscitech.2013.12.006.

3. Kmetty, Á.; Bárány, T.; Karger-Kocsis, J. Self-reinforced polymeric materials: A review. Progress in Polymer Science 2010, 35, 1288-1310, doi:10.1016/j.progpolymsci.2010.07.002.

4. Mukhopadhyay, S.; Adak, B. Single-Polymer Composites; CRC Press, 2018; ISBN 978-1-351-27222-3. 
5. KG, P.F.G.\& C. Curv Available online: https://www.curvonline.com/ (accessed on Sep 15, 2020).

6. Armordon - Advanced Fabrics / Composites - Advanced Fabrics by Thrace Plastics Pack S.A. Available online: https://www.environmental-expert.com/products/armordon-advanced-fabrics-291381 (accessed on Sep 15, 2020).

7. Friesland, M. reclame S. Pure Composites Available http://www.ditweaving.com/about_pure.php?page=pure_technology (accessed on Sep 15, 2020).

8. Marais, C.; Feillard, P. Manufacturing and mechanical characterization of unidirectional polyethylene-fibre/polyethylene-matrix composites. Composites Science and Technology 1992, 45, 247-255, doi:10.1016/0266-3538(92)90086-I.

9. Zhang, W.; Hu, Z.; Zhang, Y.; Lu, C.; Deng, Y. Gel-spun fibers from magnesium hydroxide nanoparticles and UHMWPE nanocomposite: The physical and flammability properties. Composites Part B: Engineering 2013, 51, 276-281, doi:10.1016/j.compositesb.2013.03.014.

10. Izer, A.; Bárány, T.; Varga, J. Development of woven fabric reinforced all-polypropylene composites with beta nucleated homoand copolymer matrices. Composites Science E Technology 2009, 69, 2185-2192, doi:10.1016/j.compscitech.2009.06.002.

11. Cohen, Y.; Rein, D.M.; Vaykhansky, L. A novel composite based on ultra-high-molecular-weight polyethylene. Composites Science and Technology 1997, 57, 1149-1154, doi:10.1016/S0266-3538(96)00149-2.

12. Zhang, G.; Jiang, L.; Shen, K.; Guan, Q. Self-reinforcement of high-density polyethylene/low-density polyethylene prepared by oscillating packing injection molding under low pressure. Journal of Applied Polymer Science 1999, 71, 799-804, doi:10.1002/(SICI)1097-4628(19990131)71:5<799::AID-APP13>3.0.CO;2-2.

13. Zhuang, X.; Yan, X. Investigation of damage mechanisms in self-reinforced polyethylene composites by acoustic emission. Composites Science and Technology 2006, 66, 444-449, doi:10.1016/j.compscitech.2005.07.013.

14. Lacroix, F. v.; Werwer, M.; Schulte, K. Solution impregnation of polyethylene fibre/polyethylene matrix composites. Composites Part A: Applied Science and Manufacturing 1998, 29, 371-376, doi:10.1016/S1359-835X(97)00101-2.

15. CES EduPack Software; Granta Design Limited: Cambridge, UK, 2019; Available online: https://www.ansys.com/products/materials (accessed on 30 March 2021)

16. Chukov, D.I.; Zherebtsov, D.D.; Olifirov, L.K.; Torokhov, V.G.; Maksimkin, A.V. Comparison between self-reinforced composites based on ultra-high molecular weight polyethylene fibers and isotropic UHMWPE. Mendeleev Communications 2020, 30, 49-51, doi:10.1016/j.mencom.2020.01.016.

17. Ward, I.M.; Hine, P.J. Novel composites by hot compaction of fibers. Polym. Eng. Sci. 1997, 37, 1809-1814, doi:10.1002/pen.11830.

18. Hine, P.J.; Ward, I.M.; Maaty, M.I.A.E.; Olley, R.H.; Bassett, D.C. The hot compaction of 2-dimensional woven melt spun high modulus polyethylene fibres. Journal of Materials Science 2000, 35, 5091-5099, doi:10.1023/A:1004835816735.

19. Cohen, Y.; Rein, D.M.; Vaykhansky, L. A novel composite based on ultra-high-molecular-weight polyethylene. Composites Science and Technology 1997, 57, 1149-1154, doi:10.1016/S0266-3538(96)00149-2.

20. Zherebtsov, D.; Chukov, D.; Statnik, E.; Torokhov, V. Hybrid Self-Reinforced Composite Materials Based on Ultra-High Molecular Weight Polyethylene. Materials 2020, 13, 1739, doi:10.3390/ma13071739.

21. Zherebtsov, D.; Chukov, D.; Torokhov, V.; Statnik, E. Manufacturing of Single-Polymer Composite Materials Based on U1tra-High Molecular Weight Polyethylene Fibers by Hot Compaction. J. of Materi Eng and Perform 2020, 29, 1522-1527, doi:10.1007/s11665-020-04582-7.

22. Olley, R.H.; Bassett, D.C.; Hine, P.J.; Ward, I.M. Morphology of compacted polyethylene fibres. Journal of Materials Science 1993, 28, 1107-1112, doi:10.1007/BF00400899.

23. Hadar, L.; Rein, D.; Khalfin, R.; Terry, A.; Heunen, G.; Cohen, Y. Compacted UHMWPE fiber composites: Morphology and X-ray Microdiffraction Experiments. Journal of Polymer Science Part B: Polymer Physics 2007, 45, 1535-1541, doi:10.1002/polb.21147.

24. Blaber, J.; Adair, B.; and Antoniou, A. Ncorr: Open-Source 2D Digital Image Correlation Matlab Software. Society for Experimental Mechanics, 2015. DOI: 10.1007/s11340-015-0009-1.

25. Statnik, E.S.; Uzun, F.; Salimon, A.I.; Korsunsky, A.M. New Approach for Fast Residual Strain Estimation Through Rational 2D Diffraction Pattern Processing. In Proceedings of the Analysis of Images, Social Networks and Texts; van der Aalst, W.M.P., Batagelj, V., Ignatov, D.I., Khachay, M., Kuskova, V., Kutuzov, A., Kuznetsov, S.O., Lomazova, I.A., Loukachevitch, N., Napoli, A., Pardalos, P.M., Pelillo, M., Savchenko, A.V., Tutubalina, E., Eds.; Springer International Publishing: Cham, 2020; pp. 282-288.

26. Rein, D.M.; Vaykhansky, L.; Khalfin, R.L.; Cohen, Y. Controlling the properties of single-polymer composites by surface melting of the reinforcing fibers. Polym. Adv. Technol. 2002, 13, 1046-1054, doi:10.1002/pat.271.

27. Zhu, B.; Liu, J.; Wang, T.; Han, M.; Valloppilly, S.; Xu, S.; Wang, X. Novel Polyethylene Fibers of Very High Thermal Conductivity Enabled by Amorphous Restructuring. ACS Omega 2017, 2, 3931-3944, doi:10.1021/acsomega.7b00563.

28. Ponçot, M.; Martin, J.; Hiver, J.M.; Verchère, D.; Dahoun, A. Study of the Dimensional Instabilities of Laminated Polypropylene Films during Heating Treatments. J. Appl. Polym. Sci. 2012, 125, 3385-3395, doi:10.1002/app.36450. 